\title{
Evaluation of IP Multimedia Subsystem based Mobile Mass Examination System
}

\author{
Ahmed Barnawi, Abdulrahman H. Altalhi, M. Rizwan Jameel Qureshi, Asif Irshad Khan \\ Faculty of Computing and Information Technology, King Abdul Aziz University, Jeddah, Saudi Arabia \\ ambarnawi@kau.edu.sa, ahaltalhi@kau.edu.sa,rmuhammd@kau.edu.sa, aikhan@kau.edu.sa
}

\begin{abstract}
This research is carried out to develop IP Multimedia Subsystem (IMS) based Mobile Mass Examination (MoMEx) System. MoMEx system is intended to improve on management of examination process for large number of examinees. IMS based application is considered to be the next generation mobile applications that enable developers to take advantage of mobile networks resources. IMS-based application is attributed with robustness and improved Quality of Experience (OoE) for mobile users. Such quality is needed to ensure users reliabilities on the system. In This paper, we cover the analysis and design phase of MoMEx system. We have designed set of questionnaires aimed to gathering insights how much the concept of mobile exam and assessment will be accepted among the students and faculty members. Based on the results obtained, we concluded the functional requirements of MoMEx system prior to implementation phase.
\end{abstract}

Index Terms - IP Multimedia Sub System, Mobile based Exam, Component Session Initial Protocol and Next Generation Networks

\section{INTRODUCTION}

In the recent years with the advancement of mobile wireless technologies, there is a significant shift in the academic from traditional way of teaching and examination pattern to mobile learning environment. Several universities incorporated the mobile technology into their teaching and learning environment and recognizes the potential of mobile technologies as an effective medium for teaching and assessment tools especially when there are mass students appeared in an exam (for example entrance exam for a university. There are already several research works published[1][2][3] on online E-exam systems to simplify the assessment process by automatic marking which significantly reduce the complex paper assessment work especially when there are mass students appeared in an exam. However, little research has been done on effect of the use of ubiquitous devices for teaching and learning. To investigate how far the concept of mobile exam and assessment as shown in figure 1 is accepted by the students and faculty members in King Abdul Aziz
University, Jeddah, KSA, questionnaires are used which are analyzed and result are then reported in this paper.

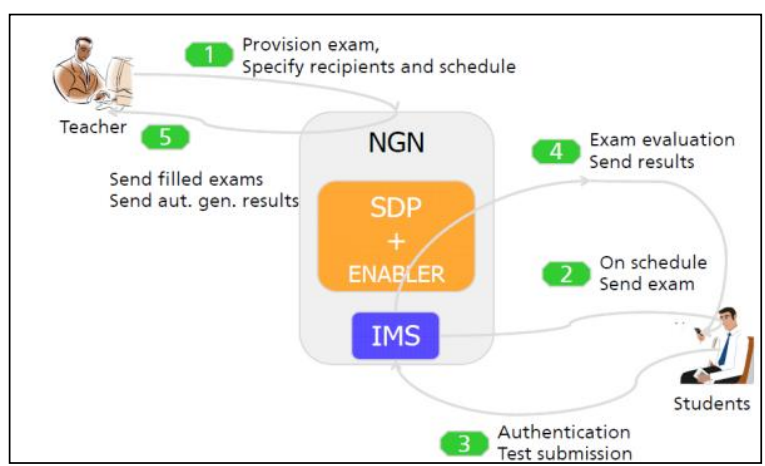

Figure 1 IMS-based mobile exam scemniro [4]

Session initial protocol (SIP) based IP Multimedia Subsystem (IMS) as shown in figure 2 is considered as the foundation stone for Next generation Network (NGN). The IMS platform is based on three layered architecture design, The IMS core network consists of mainly Transport layer, Control layer and Application layer. SIP has emerged as the vital technology for controlling communication in IP-based Networks. IMS is best described as the glue between the "global" applications world (Internet) and the mobile world. Using IMS third party developers can easy deploy their applications over mobile networks [4]. According to the standards, IMS is defined in the form of reference architecture to enable delivery of next-generation communication services of voice, data, video, wireless, and mobility over an Internet Protocol (IP) network [5]. Using IMS, applications can combine voice, text, pictures, and video in seamless call sessions, offering significant ease-of-use to subscribers and allowing service providers to drive branding through a common interface, while substantially reducing operating costs [5]. Application development cost can dramatically reduce as IMS services are facilitated by rich web development tools such as Java environments, VoiceXML forms, and other XML (eXtensible Markup Language) derivatives [5]. 




Figure 2. IMS architectural diagram Source [18]

Component based development (CBD) is ideal choices for developing mobile application, as CBD model encourage assemblies of components for systems development instead of building everything from scratch. CBD technologies comprised of implementing a component into a system through its well defined interfaces [6]. Using well-defined interfaces, a component interact with other components to accomplish a partial function of the system.

The inner structure of the component and the implementation of the interfaces are hidden to the outside. Therefore, CBSE enables a distributed and independent development of components as well as a straightforward replacement of a component by a different component in large-scale systems [7]. CBD support the development of components as reusable entities and software developers need not to reinvent the wheel if wheel is already available in the market which helps in reducing the software development time and cost as well.

We apply this model on Mobile Mass Examination (MoMEx) system that is an application attracting the interest of educational authorities around the world due to its potential convenience. MoMEx also includes an activity management application for the faculty that allows them to control the examination process in real time and to view all student data.

The paper is organized as follows: sections II covers related work Section III illustrates Case Study. Section IV contains the evaluation Section $\mathrm{V}$ contains Functionality recommendation for MoMEx system after analyzing students and faculty questionnaire and Section VI conclusion and future work.

\section{RELATED WORK}

In order to know the usage of smart phone in universities to support education, authors [8] designed and implemented several mobile based educational services at VaÈxjoÈ University. The aim of the research is to know which content and services could be delivered to the smart phones for learning and communication in context of university studies, In their project 41 students from two different courses participated for a period of three months, a survey was conducted to know the support of the services provided on smart phone, results indicated that students perceived the services as useful to learning; interestingly, and helpful in their learning. In the paper the author [8] recommended mobile services to be implemented in higher education to improve the usability, institutional support and tailored educational content purposes.

The author [9] in his research finds the state of art tools and benefits of mobile wireless technology usage in higher education across the globe. Three popular mobile wireless technologies are used in higher education and identified that each one requires different technical infrastructure to access to network resources, the three technologies they explored were wireless computers, PDAs, and web-enabled mobile phones. Issues related to each three technologies must be study before it implemented in the higher education and one such issue is security. How to achieve educational goals administrators, educators, and students must think critically to determine how to use the new technologies without it is virtually impossible to study any subject of mobile wireless technologies in higher education [9].

Most of the Mobile Learning Applications uses multimedia data such as video clips, images and documents, the authors [8] in their research analyzed and investigated for a need of fast and reliable data storage and retrieval. [10] proposed a Database Management Architecture for an Innovative Evaluation System based on Mobile Learning Applications for faster data storage and retrieval. Emphases of the investigation were for high throughput so as to support multimedia for Mobile Learning Applications development.

Reference [11] designed and implemented Online Scoring System and the concept can be helpful in designing mobile based assessment system or online examination system. How to design and implement scoring system and various functionality required for scoring system were also discussed in the paper. The system was practically implemented and provided satisfactory positive result [11].

Reference [12] implements a prototype system named Mobile Exam System (MES) is implemented on Apple iOS and Google Android OS. The aim of the research is to simply the examination management and assessment process in the universities. The verification and validation studies of MES can be said to be successful [12]. MES was well designed and developed some of the features of the system as reported in the paper are, Interface designed for MES was simple, and easy to use, System was Efficiency and secured as the main security concerns of the system were the authentication, privacy, and information encryption [12].

Jiang and Yang [13] used a component-based service framework for mobile applications. The objective of this research is to develop a service 
creation framework using the domain of mobile service engineering. Im [14] conducted a research in support of CBD technology in mobile applications.

Maria Is Po. [15] studied delay-sensitive and nonsensitive applications performance such as chat and messaging services in UMTS system mainly focusing on the UMTS SIP-based service. [15] presented a performance analysis of IP based packet-switched UMTS services. The results presented in the paper showed SIP signaling introduces a large transmission delay in the network, to reduce the transmission delay authors [15] suggested decrease number of messages exchanged during the SIP procedures and reduction in number of network elements by collocating them.

The author [16] proposed IMS and SIP based prototype framework for sensor based application development, the aim of the research is to study the appropriateness of IP Multimedia Subsystem for sensor-based applications and the framework was analyzed on medical observing aid prototype such as distance monitoring of vital medical parameters, realtime medical data transfer (telemedicine). The prototype is used for measurement of time dependency of sent, received and played packets [16]

\section{Case Study}

Our approach evolved two separate studies by conducting survey based on questionnaire. In first study, Comprehensive questionnaire comprising of 23 closed ended questions were compiled and given to the student to know their perception on present manual system and proposed mobile based examination system. In the second study Comprehensive questionnaire comprising of 24 closed ended questions were prepared and given to the faculty for their perception on present manual system and proposed mobile based examination system.

The purpose of this pilot study was to investigate students and faculty response to Mobile based examination system and perception of MOMEX as a mean of promoting and to adopt in mass level examination process in the university. The participants in this study were 56 undergraduate and 20 faculty members at faculty of Computing and Information Technology (FCIT), KAU, Jeddah, KSA. Statistical analysis has been done on the basis of data gathered through distribution of questionnaire to the student and faculty, questions were asked related to Applicability, Usability (Appearance), Affective (Factors),Pedagogy, Security and Technicality categories. Questionnaires were designed based on likert scale 1 to 5 that is most commonly used in research community that employs questionnaires. Points were labeled as shown in Table 1.
Table1. Likert scale

\begin{tabular}{|l|l|}
\hline 5 & Strongly Agreed (SA) \\
\hline 4 & Agree (A) \\
\hline 3 & Neutral (N) \\
\hline 2 & Disagree (D) \\
\hline 1 & Strongly Disagree (SD) \\
\hline
\end{tabular}

The analysis result is represented using frequency tables and bar charts showing the exact degree of analysis. It is very important to know about the types of mobile devices student carry and their subscribed telecommunication services for the successful implementation of the mobile based assessment application which requires mobile devices with SIP (Session Initial Protocol) related feature, as client mobile will uses SIP as a medium to interact the IMS (Internet Protocol based Multimedia sub systems) platform.

The purpose of IMS is to provide the Internet service to the user anywhere and anytime through the mobile phone technology. IMS is designed with building blocks, giving telecommunication operators the ability to deliver new services in a more flexible way. The introduction of IMS networks brings a networkagnostic server delivery model to the server providers. They are able to deliver converged services, in combination of messaging, video, data and etc, regardless of the type of the network, yet achieve a better quality of service (QoS). IMS network architecture has three main layers, which are transport layer, control layer and service layer. The separation of layers makes it easy to standardize the interfaces and interconnect the systems [17]. Now a day's most of the smart phones have SIP related features provided by their manufacturers.

\section{Evaluation}

Table 2. Frequency Chart for Handset brands

\begin{tabular}{|l|l|l|}
\hline Handset Brand & Frequency & \%age owned \\
\hline Apple IPhone & 23 & 27.1 \\
\hline Blackberry & 41 & 48.2 \\
\hline HTC & 1 & 1.2 \\
\hline Nokia & 11 & 12.9 \\
\hline Sony Ericsson & 0 & 0.0 \\
\hline Motorola & 5 & 5.9 \\
\hline Samsung & 3 & 3.5 \\
\hline Others & 1 & 1.2 \\
\hline Total & 85 & 100.0 \\
\hline
\end{tabular}


Table 3. Frequency Chart for Mobile Services

\begin{tabular}{|l|l|l|}
\hline Services & Frequency & \%age \\
\hline $2 \mathrm{G}$ & 4 & 6.9 \\
\hline $3 \mathrm{G}$ & 45 & 77.6 \\
\hline $4 \mathrm{G}$ & 6 & 10.3 \\
\hline Others & 3 & 5.2 \\
\hline Total & 58 & 100.0 \\
\hline
\end{tabular}

Tables 2 and 3 provide respondents types of mobile services they scribed and smart phone brands they owned, the result shows Blackberry $(48.2 \%)$ is a favorite brands among students after that Apple IPhone $(27.1 \%)$ and then Nokia (12.9\%) as far as subscribing mobile service is concerned most of the student subscribed 3G about $77.6 \%$, also, $10.3 \%$ students subscribed $4 \mathrm{G}$ and $6.9 \% 2 \mathrm{G}$. Further, results indicate that some students owned more than one handset (different brand). Following are the detail analysis based on the categories.

\section{Applicability category}

To find out the feeling and acceptance of mobile based assessment in comparison with traditional paper based exam three questions were asked in student questionnaire under applicability category, Questions under this category are listed in appendix 1 and their analyses are as follows

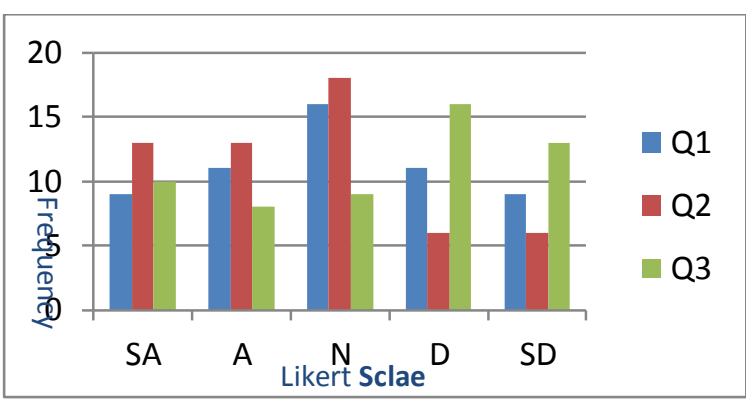

Figure 3. Graphical representation of Applicability category

Table 4. Frequency Chart for Applicability category

\begin{tabular}{|c|c|c|c|c|c|c|c|}
\hline & Q1 & $\%$ age & Q2 & $\%$ age & Q3 & $\%$ age & Avg. \\
\hline SA & 9 & 16 & 13 & 23 & 10 & 18 & 19 \\
\hline A & 11 & 20 & 13 & 23 & 8 & 14 & 19 \\
\hline N & 16 & 29 & 18 & 32 & 9 & 16 & 26 \\
\hline D & 11 & 20 & 6 & 11 & 16 & 29 & 20 \\
\hline SD & 9 & 16 & 6 & 11 & 13 & 23 & 17 \\
\hline Tot. & 56 & 100 & 56 & 100 & 56 & 100 & 100 \\
\hline
\end{tabular}

Discussion: Table 4 and Figure 3 shows frequency and barchart for Applicability category, out of 56 populations, as far as applicability is concerned on an average $38 \%$ students agreed that mobile based exam assessment is a better over traditional exam and they believe automatic assessment is fairer over manual assessment, also voice based assessment is supported by them where as $26 \%$ neither agreed nor disagree and $37 \%$ are disagreeing.

\section{Usability (Appearance)}

To find out how easy student's feel while using the prototype of the system, In student questionnaire screen shot figure 4,5,6,7 of the prototype of the proposed system were provided to find the support for usability, Questions under this category are listed in appendix 1 and their analyses are as follows

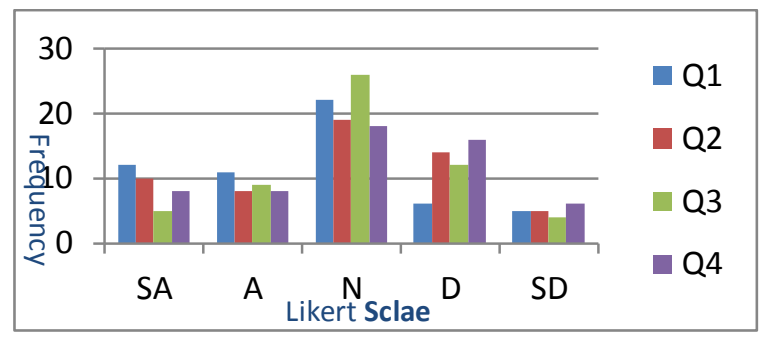

Figure 4. Graphical representation of Usability category

TABLE 5. Frequency Chart of Usability category

\begin{tabular}{|c|c|c|c|c|c|c|c|c|c|}
\hline & $\begin{array}{l}\% \\
\text { age }\end{array}$ & Q2 & $\begin{array}{c}\% \\
\text { age }\end{array}$ & Q3 & $\begin{array}{c}\% \\
\text { age }\end{array}$ & Q4 & $\begin{array}{c}\% \\
\text { age }\end{array}$ & Avg. \\
\hline SA & 12 & 21.4 & 10 & 18 & 5 & 8.9 & 8 & 14.3 & 15.6 \\
\hline A & 11 & 19.6 & 8 & 14 & 9 & 16 & 8 & 14.3 & 16.1 \\
\hline N & 22 & 39.3 & 19 & 34 & 26 & 46 & 18 & 32.1 & 37.9 \\
\hline D & 6 & 10.7 & 14 & 25 & 12 & 21 & 16 & 28.6 & 21.4 \\
\hline SD & 5 & 8.93 & 5 & 8.9 & 4 & 7.1 & 6 & 10.7 & 8.9 \\
\hline Tot. & 56 & 100 & 56 & 100 & 56 & 100 & 56 & 100 & 100 \\
\hline
\end{tabular}

Discussion: Table 5 and Figure 4 shows frequency and barchart for usability category, out of 56 populations on an average $31.7 \%$ students finds it is easy to use the prototype of the system, as Sequence of screens and interface of this system is pleasant, They find easy while reading characters on the screen, also, naming convention, organization of information make the system easy to understand and to use where as $37.9 \%$ of the students were neutral i.e. neither agreed nor disagree and around $20 \%$ were disagreeing. 


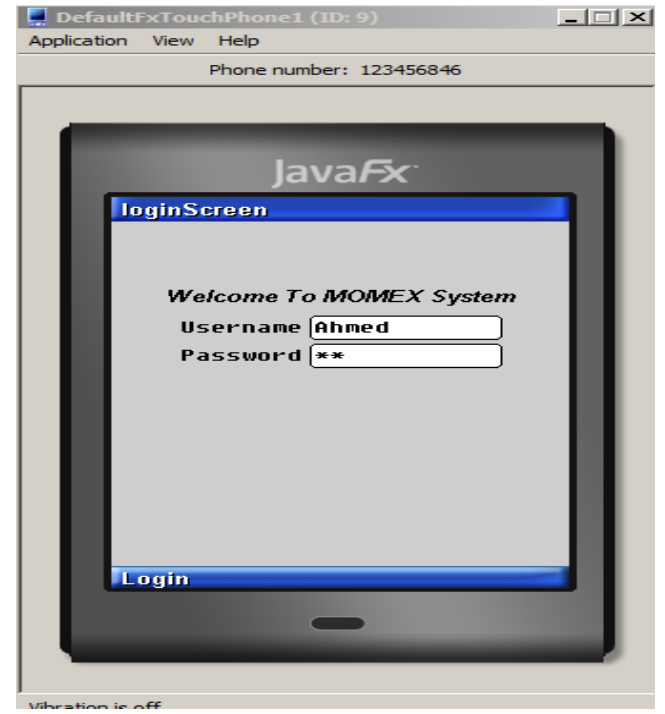

Figure 5- Login Screen



Figure 6- Student Dashboard

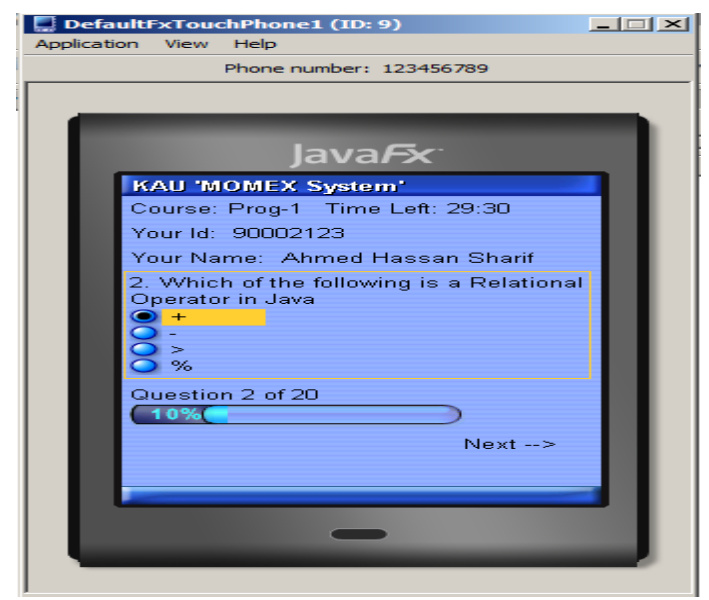

Figure 7- Exam Screen

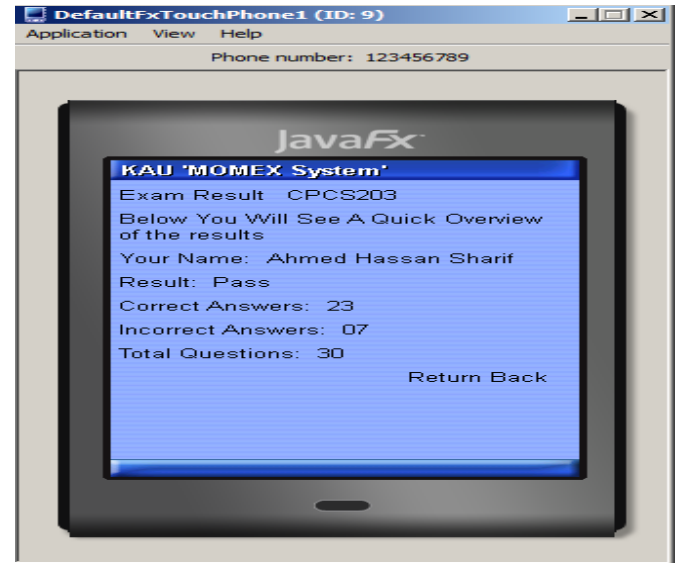

Figure 8- Exam Result

\section{Affective (Factors)}

To find out the factors that might affect student performance while they use mobile device for assessment purposes, Questions under this category are listed in appendix 1 and their analyses are as follows

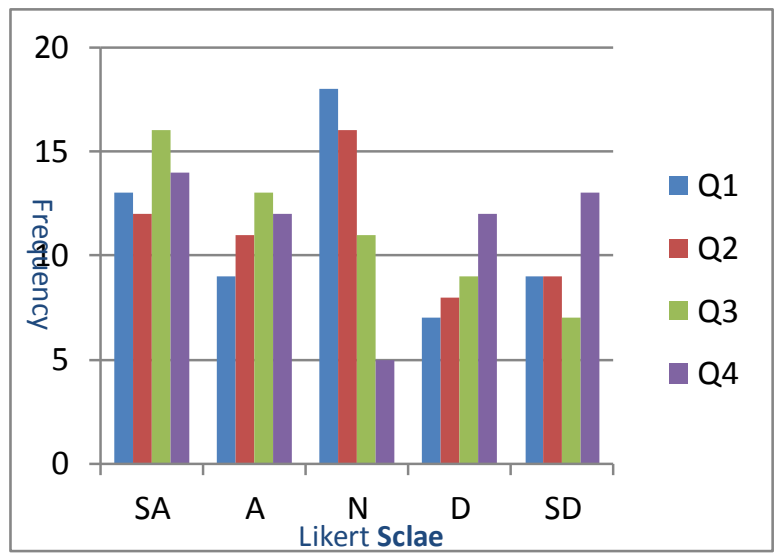

Figure9. Graphical representation of Affective category

TABLE 6. Frequency Chart of Affective category

\begin{tabular}{|c|c|c|c|c|c|c|c|c|c|}
\hline & Q1 & \%age & Q2 & \%age & Q3 & \%age & Q4 & \%age & Avg \\
\hline SA & 13 & 23.2 & 12 & 21.4 & 16 & 28.6 & 14 & 25 & 24.6 \\
\hline A & 9 & 16.1 & 11 & 19.6 & 13 & 23.2 & 12 & 21.4 & 20.1 \\
\hline N & 18 & 32.1 & 16 & 28.6 & 11 & 19.6 & 5 & 8.93 & 22.3 \\
\hline D & 7 & 12.5 & 8 & 14.3 & 9 & 16.1 & 12 & 21.4 & 16.1 \\
\hline SD & 9 & 16.1 & 9 & 16.1 & 7 & 12.5 & 13 & 23.2 & 17.0 \\
\hline Tot. & 56 & 100 & 56 & 100 & 56 & 100 & 56 & 100 & 100 \\
\hline
\end{tabular}

Discussion: Table 6 and Figure 9 shows frequency and barchart, out of 56 populations $39.3 \%$ agreed that there are chances of stress if assessed in mobile devices, while 28.6 doesn't agree that there will be stress while appearing in exam on the mobile devices, $32.1 \%$ of the 
students were neutral. Regarding recommending mobile based exam in universities $41 \%$ recommend to be effective tool to be opted in the universities, on an average $44.7 \%$ students think it is bit hard to concentrate while going for mobile based examination system and $33.1 \%$ feels no difference in concentration on either way (mobile or traditional examination)

\section{Pedagogy category}

To student perceptions on improvement in learning process by the use of mobile based assessment. Questions under this category are listed in appendix 1 and their analyses are as follows

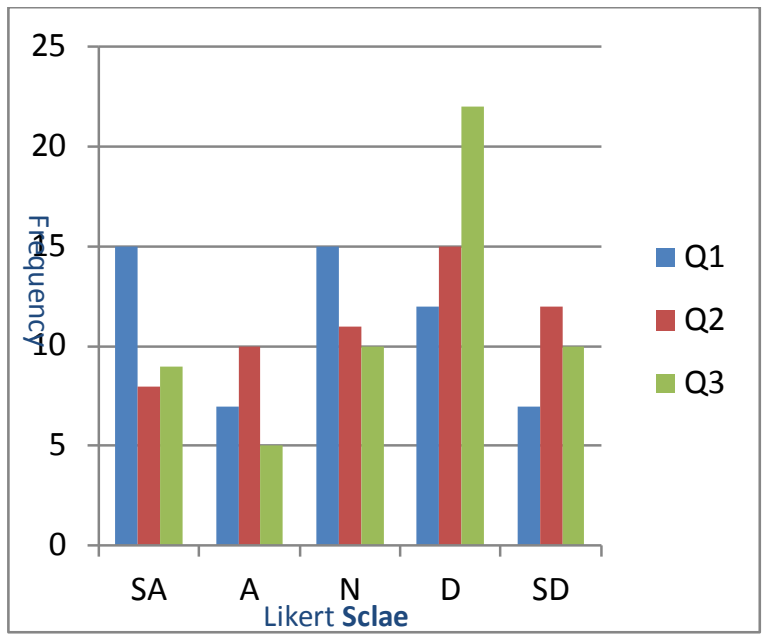

Figure 10. Graphical representation of Pedagogy category

TABLE 7. Frequency Chart of Pedagogy category

\begin{tabular}{|l|l|l|l|l|l|l|l|}
\hline & Q1 & $\begin{array}{l}\% \\
\text { age }\end{array}$ & Q2 & $\begin{array}{l}\% \\
\text { age }\end{array}$ & Q3 & $\begin{array}{l}\% \\
\text { age }\end{array}$ & Avg. \\
\hline SA & 15 & 27 & 8 & 14 & 9 & 16 & 19 \\
\hline A & 7 & 13 & 10 & 18 & 5 & 8.9 & 13 \\
\hline $\mathrm{N}$ & 15 & 27 & 11 & 20 & 10 & 18 & 21 \\
\hline $\mathrm{D}$ & 12 & 21 & 15 & 27 & 22 & 39 & 29 \\
\hline $\mathrm{SD}$ & 7 & 13 & 12 & 21 & 10 & 18 & 17 \\
\hline Tot. & 56 & 100 & 56 & 100 & 56 & 100 & 100 \\
\hline
\end{tabular}

Discussion: Table 7 and Figure 10 shows frequency and barchart for pedagogy category, results shows that on average $32 \%$ students agreed that immediate results by mobile based system could help them in their learning while $21 \%$ were neutral while $46 \%$ agreed that Mobile based assessment is just a gimmick and it does not really benefit learning.

\section{Security}

As the system is mobile application it is very interesting to know how the student feel regarding the security concerned The main security concerns of the system are the authentication, privacy, and information encryption, Questions under this category are listed in appendix 1 and their analyses are as follows

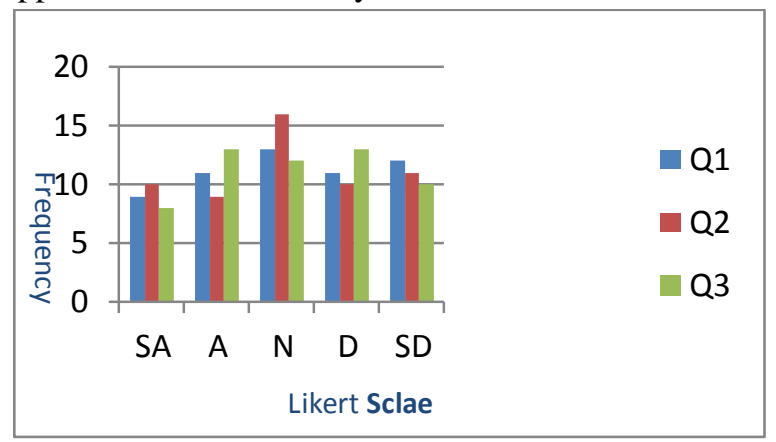

Figure 11. Graphical representation of security category

TABLE 8. Frequency Chart of security category

\begin{tabular}{|c|c|c|c|c|c|c|c|}
\hline & Q1 & $\%$ age & Q2 & $\%$ age & Q3 & $\%$ age & Avg. \\
\hline SA & 9 & 16 & 10 & 18 & 8 & 14 & 16.1 \\
\hline A & 11 & 20 & 9 & 16 & 13 & 23 & 19.6 \\
\hline N & 13 & 23 & 16 & 29 & 12 & 21 & 24.4 \\
\hline D & 11 & 20 & 10 & 18 & 13 & 23 & 20.2 \\
\hline SD & 12 & 21 & 11 & 20 & 10 & 18 & 19.6 \\
\hline Tot. & 56 & 100 & 56 & 100 & 56 & 100 & 100 \\
\hline
\end{tabular}

Discussion: Table 8 and Figure 11 shows frequency and barchart under security category, results shows that on average $35.7 \%$ students agreed that mobile based system is secured than paper-based assessment and $24.5 \%$ were neutral while $40 \%$ not agreed that Mobile based assessment is as secure as paper-based assessment.

\section{Technicality}

under technicality category we tried to find out student's perception on the mobile technology, its complex nature, accuracy and the result expectation from the system. Questions under this category are listed in appendix 1 and their analyses are as follows

Discussion: Table 9 and Figure 12 shows frequency and barchart under technicality category, results shows that on average $36.7 \%$ students trust the mobile based technology for exam evaluation as computers don't suffer from human error, result, also indicated that same percentage of students think that randomized questions from an exam bank may sometimes bring easier questions in the exam, while $28.9 \%$ students were neutral and $34 \%$ were not agreed. 


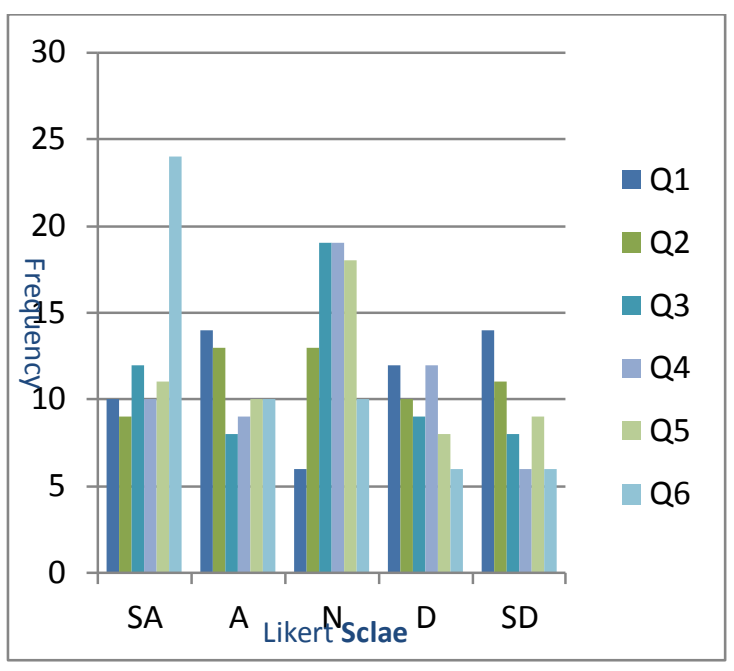

Figure12. Graphical representation of Technicality category

TABLE 9. Frequency Chart of Technicality category

\begin{tabular}{|c|c|c|c|c|c|c|c|c|c|c|}
\hline & $\begin{array}{c}\mathrm{Q} \\
1\end{array}$ & $\begin{array}{c}\% a g \\
\mathrm{e}\end{array}$ & $\begin{array}{l}\mathrm{Q} \\
2\end{array}$ & $\begin{array}{c}\% a g \\
\mathrm{e}\end{array}$ & $\begin{array}{l}\mathrm{Q} \\
3\end{array}$ & $\begin{array}{c}\% \text { ag } \\
\mathrm{e}\end{array}$ & $\begin{array}{l}\mathrm{Q} \\
4\end{array}$ & $\begin{array}{c}\text { \%ag } \\
\mathrm{e}\end{array}$ & Q5 & Avg \\
\hline $\begin{array}{l}\mathrm{S} \\
\mathrm{A}\end{array}$ & 10 & 17.9 & 9 & 16 & $\begin{array}{l}1 \\
2\end{array}$ & 21 & $\begin{array}{l}1 \\
0\end{array}$ & 19.7 & 24.0 & 30.6 \\
\hline $\mathrm{A}$ & 14 & 25 & $\begin{array}{l}1 \\
3\end{array}$ & 23 & 8 & 14 & 9 & 16.1 & 10.0 & 18.8 \\
\hline $\mathrm{N}$ & 6 & 10.7 & $\begin{array}{l}1 \\
3 \\
\end{array}$ & 23 & $\begin{array}{l}1 \\
9 \\
\end{array}$ & 34 & $\begin{array}{l}1 \\
9 \\
\end{array}$ & 33.9 & 10.0 & 21.7 \\
\hline $\mathrm{D}$ & 12 & 21.4 & $\begin{array}{l}1 \\
0\end{array}$ & 18 & 9 & 16 & $\begin{array}{l}1 \\
2\end{array}$ & 21.4 & 6.0 & 15.0 \\
\hline $\begin{array}{l}\mathrm{S} \\
\mathrm{D}\end{array}$ & 14 & 25 & $\begin{array}{l}1 \\
1\end{array}$ & 20 & 8 & 14 & 6 & 10.7 & 6.0 & 14.1 \\
\hline $\begin{array}{c}\mathrm{T} \\
\text { ot. }\end{array}$ & 56 & 100 & $\begin{array}{l}5 \\
6\end{array}$ & 100 & $\begin{array}{l}5 \\
6\end{array}$ & 100 & $\begin{array}{l}5 \\
6\end{array}$ & 100 & 56 & 100 \\
\hline
\end{tabular}

\section{Faculty}

Twenty faculty members at faculty of Computing and Information Technology (FCIT), KAU, Jeddah, KSA, took part in the second survey to know support and view of faculty members for mobile based examination system. Questions were prepared related to the following category Applicability, Usability (Appearance), (Factors), Security and Technicality was asked in the survey.

\section{Technicality category}

Under Technicality category questions were asked related to problems in the current paper based exam and level of need for automatic assessment of exams, also, suggestions was requested to minimize the possibility of cheating. Questions under this category are listed in appendix 1 and their analyses are as follows

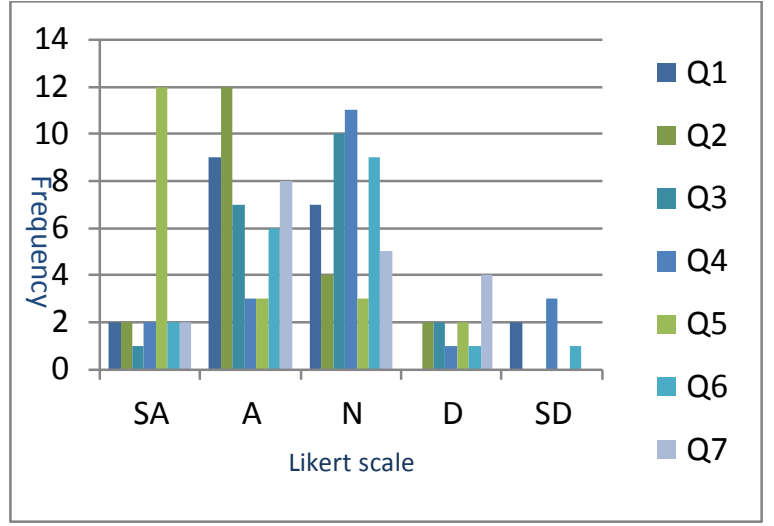

Figure 13. Graphical representation of Technicality category

TABLE 10. Faculty Frequency Chart of Technicality category

\begin{tabular}{|c|c|c|c|c|c|c|c|c|c|c|c|c|c|c|c|}
\hline & Q1 & \%age & Q2 & \%age & Q3 & \%age & Q4 & \%age & Q5 & \%age & Q6 & \%age & Q7 & \%age & Avg. \\
\hline SA & 2 & 10 & 2 & 10 & 1 & 5 & 2 & 10 & 12 & 60 & 2 & 11 & 2 & 11 & 16.6 \\
\hline A & 9 & 45 & 12 & 60 & 7 & 35 & 3 & 15 & 3 & 15 & 6 & 32 & 8 & 42 & 34.8 \\
\hline N & 7 & 35 & 4 & 20 & 10 & 50 & 11 & 55 & 3 & 15 & 9 & 47 & 5 & 26 & 35.5 \\
\hline D & 0 & 0 & 2 & 10 & 2 & 10 & 1 & 5 & 2 & 10 & 1 & 5 & 4 & 21 & 8.8 \\
\hline SD & 2 & 10 & 0 & 0 & 0 & 0 & 3 & 15 & 0 & 0 & 1 & 5 & 0 & 0 & 4.3 \\
\hline Tot. & 20 & 100 & 20 & 100 & 20 & 100 & 20 & 100 & 20 & 100 & 19 & 100 & 19 & 100 & 100.0 \\
\hline
\end{tabular}

Discussions: Table 10 and Figure 13 shows frequency and barchart on an average around $52 \%$ faculty members agreed that the current system of manual assessment is very time consuming and requires a lot of effort and consumes enormous resources and hence there is a level of need for automatic assessment of exams especially when group of student is too large in a course and around $35 \%$ were neutral while $13 \%$ didn't agreed. Most of the faculty agreed that randomizing questions in exam can reduce cheating, also, they convinced that paper leakage issue can be overcome with the use of mobile based examination system.

\section{Usability category}

Under usability category questions were asked related to the effectiveness, efficiency, and satisfaction of faculty with the present manual assessment system and proposed mobile based assessment system. Questions under this category are listed in appendix 1 and their analyses are as follows 


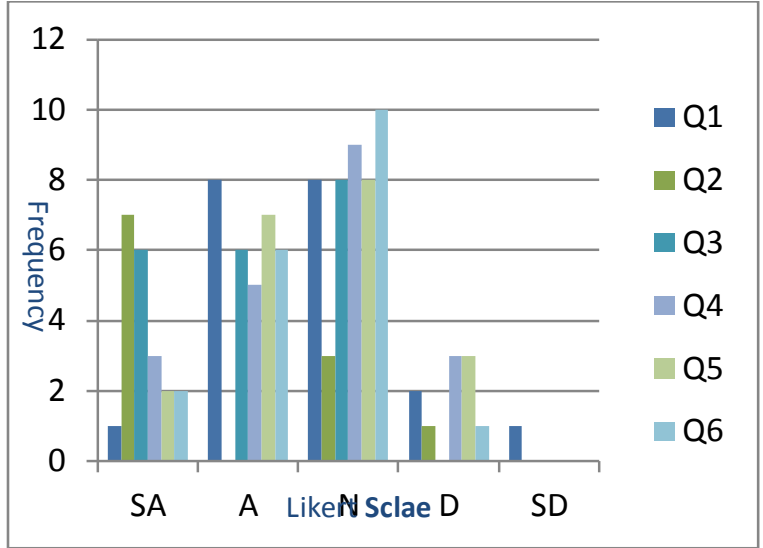

Figure 14. Graphical representation of Usability category

TABLE 11. Faculty Frequency Chart of Usability category

\begin{tabular}{|c|c|c|c|c|c|c|c|c|c|c|c|c|c|}
\hline & Q1 & \%age & Q2 & \%age & Q3 & \%age & Q4 & \%age & Q5 & \%age & Q6 & \%age & Avg. \\
\hline SA & 1 & 5 & 7 & 64 & 6 & 30 & 3 & 15 & 2 & 10 & 2 & 11 & 22 \\
\hline A & 8 & 40 & 0 & 0 & 6 & 30 & 5 & 25 & 7 & 35 & 6 & 32 & 27 \\
\hline N & 8 & 40 & 3 & 27 & 8 & 40 & 9 & 45 & 8 & 40 & 10 & 53 & 41 \\
\hline D & 2 & 10 & 1 & 9 & 0 & 0 & 3 & 15 & 3 & 15 & 1 & 5 & 9 \\
\hline SD & 1 & 5 & 0 & 0 & 0 & 0 & 0 & 0 & 0 & 0 & 0 & 0 & 1 \\
\hline Tot. & 20 & 100 & 11 & 100 & 20 & 100 & 20 & 100 & 20 & 100 & 19 & 100 & 100 \\
\hline
\end{tabular}

Discussions: Table 11 and Figure 14 shows frequency and barchart under usability category, the result shows that on an average around $49 \%$ faculty members agreed that the current system of manual setting of exam paper is very difficult as it is a repetitive job, also, they agreed that searching history record is very difficult job in present manual system, they further agreed that Mobile Based Examination enhance learning process and better safeguards against tampering and around $41 \%$ were neutral while $10 \%$ didn't agreed and find no problem in present manual assessment of exam and believed that mobile based exam will not produce any enhancement in learning process.

\section{Security category}

Faculty mostly worried about the cheating activities very common during the exam by some students, so question were asked if mobile based examination system can reduce cheating activity and how can it be achieved. Questions under this category are listed in appendix 1 and their analyses are as follows

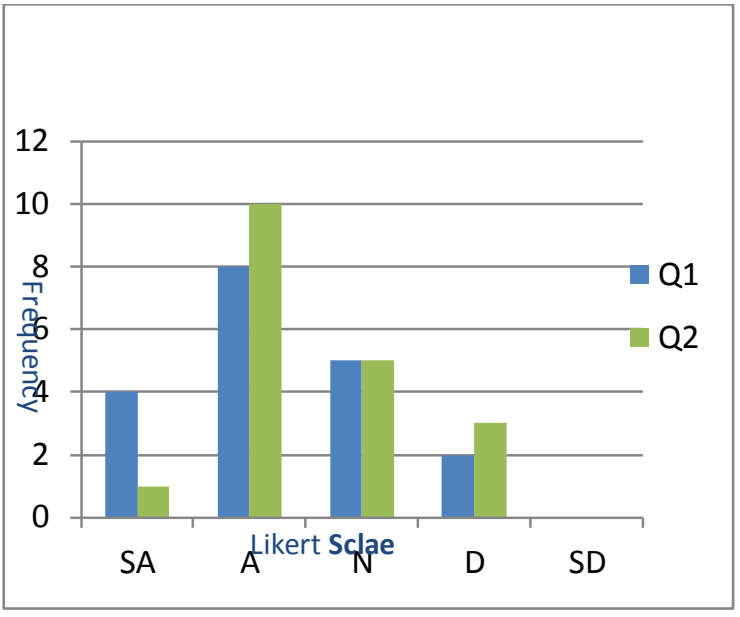

Figure15. Graphical representation of Security category

TABLE 12. Faculty Frequency Chart of Security category

\begin{tabular}{|c|c|c|c|c|c|}
\hline & Q1 & \%age & Q2 & \%age & Avg. \\
\hline SA & 4 & 21 & 1 & 5 & 13 \\
\hline A & 8 & 42 & 10 & 53 & 47 \\
\hline N & 5 & 26 & 5 & 26 & 26 \\
\hline D & 2 & 11 & 3 & 16 & 13 \\
\hline SD & 0 & 0 & 0 & 0 & 0 \\
\hline Tot. & 19 & 100 & 19 & 100 & 100 \\
\hline
\end{tabular}

Discussions: Table 12 and Figure 15 shows frequency and barchart under security category, the result shows that on an average around $60 \%$ faculty members agreed that it is difficult to cheat during mobile based examination system as questions are generated from a question pool and around $26 \%$ were neutral while $13 \%$ didn't agreed and find no improvement in security related to cheating during the exam.

\section{Applicability category}

Under this category questions were asked regarding the acceptance or support of mobile based assessment, its improvement in assessment process in comparison with the present manual assessment process. Questions under this category are listed in appendix 1 and their analyses are as follows 


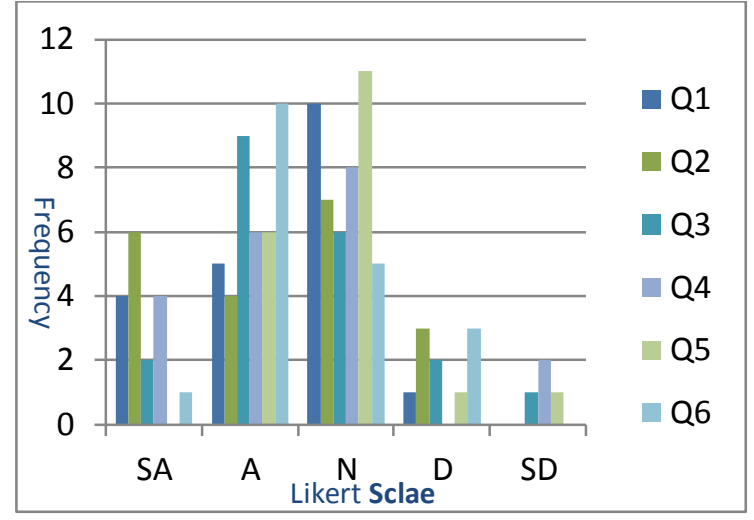

Figure16. Graphical representation of Applicability category

TABLE 13. Faculty Frequency Chart of applicability category

\begin{tabular}{|c|c|c|c|c|c|c|c|c|c|c|c|c|c|}
\hline & Q1 & \%age & Q2 & \%age & Q3 & \%age & Q4 & \%age & Q5 & \%age & Q6 & \%age & Avg, \\
\hline SA & 4 & 20 & 6 & 30 & 2 & 10 & 4 & 20 & 0 & 0 & 1 & 5 & 14 \\
\hline A & 5 & 25 & 4 & 20 & 9 & 45 & 6 & 30 & 6 & 32 & 10 & 53 & 34 \\
\hline N & 10 & 50 & 7 & 35 & 6 & 30 & 8 & 40 & 11 & 58 & 5 & 26 & 40 \\
\hline D & 1 & 5 & 3 & 15 & 2 & 10 & 0 & 0 & 1 & 5 & 3 & 16 & 9 \\
\hline SD & 0 & 0 & 0 & 0 & 1 & 5 & 2 & 10 & 1 & 5 & 0 & 0 & 3 \\
\hline Tot. & 20 & 100 & 20 & 100 & 20 & 100 & 20 & 100 & 19 & 100 & 19 & 100 & 100 \\
\hline
\end{tabular}

Discussions: Table 13 and Figure 16 shows frequency and barchart under applicability category, the result shows that on an average around $48 \%$ faculty members accepted Mobile based examination system compared to traditional paper based exam, they think automatic assessment is fairer and believe that handwriting on an exam may influenced the scores to some degree and around $40 \%$ were neutral while $12 \%$ didn't agreed assessment using mobile technology and find no improvement in assessment process.

\section{FUNCTIONALITY RECOMMENDATION FOR MOMEX SYSTEM AFTER ANAL YZING STUDENTS AND FACULTY QUESTIONNAIRE}

Most of the main problems and issues with the current manual examination system are analyzed and functionality needed in MOMEX system are analyzed and recommended based on the surveyed data. As mentioned in the previous section of the paper, MOMEX system improves the present manual system in the following category Applicability, Usability (Appearance), Affective (Factors), Pedagogy, Security and Technicality, further details are listed in Table 14.

Table 14. Problems in manual examination assessment system and functionality needed

\begin{tabular}{|c|c|}
\hline $\begin{array}{l}\text { Problems and issues with current examination } \\
\text { process }\end{array}$ & Functionality required in MoMEx \\
\hline $\begin{array}{l}\text { Faculty find it hard to prepare exams and quizzes } \\
\text { every semester keeping in consideration that } \\
\text { questions cannot be repeated from last semesters'. }\end{array}$ & $\begin{array}{l}\text { M-Exam, Quizzes } \\
\square \text { MoMEx system allows faculty to store the } \\
\text { questions one time in a question bank. } \\
\square \text { Faculty can choose randomizing option so that } \\
\text { question paper will be generated automatically from a } \\
\text { random pool. }\end{array}$ \\
\hline $\begin{array}{l}\text { Faculty find some time it is very hard and time- } \\
\text { consuming to manually mark the exam papers } \\
\text { especially when student enrolment is very high in a } \\
\text { particular course. }\end{array}$ & $\begin{array}{l}\text { Auto Marking and Report generation } \\
\text { (Result analysis) } \\
\square \text { MoMEx system automatically evaluate the } \\
\text { question paper attempted by student. } \\
\square \text { MoMEx system inform the student about their } \\
\text { result either immediately or once approved by the } \\
\text { faculty. } \\
\square \text { MoMEx system generate result analysis report, } \\
\text { helpful to know the overall student performance in a } \\
\text { particular course. }\end{array}$ \\
\hline Students / faculty authentication & $\begin{array}{l}\text { Login } \\
\square \text { A login mechanism that could verify and } \\
\text { authenticate the student, or faculty to access to the } \\
\text { Exam database. }\end{array}$ \\
\hline Auto E-mail notification & $\begin{array}{l}\text { The system will automatically sent reminders for } \\
\text { exam schedule and related information. }\end{array}$ \\
\hline
\end{tabular}




\begin{tabular}{|l|l|}
\hline Keeping track of student's examination history & Mobile -records management \\
manually & $\square$ Store every exam attempt in the database. \\
& $\square$ Store, view and update request records. \\
& $\square$ Sort, search and view the records or information as \\
requested from previously attempted exams.
\end{tabular}

\section{Conclusions ANd Future Work}

The use of Mobile-based assessment in higher education gives possibility for assessing more competencies than it is possible in the traditional paper-and-pencil based exam. Functional plans were developed, and also a relational database for supporting them. After taking these steps, we also made prototype user interfaces for various device classes. Finally, summarizing the actual requirements, our need for supporting possible future extensions, and the feasibility issues for deployment, we selected the target platforms for implementing the mobile client applications. In this paper, we reported an ongoing research by our group towards putting together a platform as a testbed used for NGN application development. A survey is conducted, among the faculty and students of King Abdul Aziz University, to identify the main problems of current examination system and gather the functional requirements of the new system.

Fulfilling our prior expectations, we successfully identified the specific functional and architectural requirements for mobile assessment system. Future work is the prototype simulation of the IMS-based mass examination system to validate the functional and non functional requirements of the system.

\section{ACKNOWLEDGMENT}

The authors would like to thank King Abdulaziz City for Science and Technology (KACST), Saudi Arabia for funding this ongoing research project number 29-324.

\section{REFERENCES}

[1] Y. Zhenming, Z. Liang and Z. Guohua. A Novel Web-Based Online Examination System for Comp. Science Education. In 33rd ASEE/IEEE Frontiers Education Conf., S3F-7-S3F-10, 2003.

[2] Magdi Z. R., Mahmoud S. K., Ahmed E. H., and Mahmoud A. Z. An Arabic Web-Based Exam Management System, In International Journal of Electrical \& Computer Sciences IJECS-IJENS Vol: 10 No: 01, 2008.

[3] Yuan Zhenming, Zhang Liang, Zhan Guohua. A Novel Web-Based Online Examination System for Computer Science Education. In 26rd ASEE/IEEE Frontiers Education Conference, S3F-7-S3F-10. 2003
[4] A. Barnawi, Nadine A, M. Emran and Asif I. Khan. Deploying SIP-based Mobile Exam Application onto Next Generation Network testbed. In first Saudi International Electronics, Communications and Electronics Conference (SIECPC'11), KS A. . 2011.

[5] James Wright. The Architecture and Benefits of IMS. Dialogic Corporation, Retrieved on November $18^{\text {th }} 2011$ from

http://www.konnetic.com/Documents/KonneticIMSSer vices AndRevenue.pdf

[6] H. Hansson, M. Åkerholm, I. Crnkovic, M. Törngren. SaveCCM - a Component Model for Safety-Critical Real-Time Systems. In Proceedings of the 30th EUROMICRO Conference (EUROMICRO’04), France, 2004.

[7] Research Areas of the Software Engineering Group, Retrieved on November 18th 2011 from, http://www.cs.uni-paderborn.de/en/researchgroup/software-engineering/research/researchareas.html

[8] MARCELO MILRAD1 and MICHELE H. JACKSON. Designing and Implementing Educational Mobile Services in University Classrooms Using Smart Phones and Cellular Networks. In Int. J. Engng Ed. Vol. 24, No. 1, p. 84+91, 2008

[9] Kim, S.H., Mims, C., \& Holmes, K.P. An introduction to current trends and benefits of mobile wireless technology use in higher education. In AACE Journal, 14(1), p. 77-100, 2006.

[10] Lu, Joan, Sundaram, Aswin, Zhaozong, Meng, Arumugam, Vidyapriyadarshini and Gehao, Lu. Mobile Exam System - MES: Architecture for Database Management. In The International Conference on Education \& Learning in Mobile Age - CELMA, Lake District, United Kingdom. June 1-2, 2011.

[11] GUO Ping, ZHANG Hai-yan, DENG Yi-wen. The Design and Implementation of Online Scoring System. In IEEE School of Computer Science, Chongqing University, Chongqing, 400044, China, 2009.

[12] ZhaozongMeng and Joan Lu. Implementing the Emerging Mobile Technologies in Facilitating Mobile Exam System. In $2^{\text {nd }}$ International Conference on Networking and Information Technology IPCSIT, IACSIT Press, Singapore, vol.17, 2011.

[13] Michal Jiang and Zhihua Yang. A Component-Based Service Framework for Mobile Applications. In 2006 
International Conference on Information Reuse and Integration, Waikoloa Village, HI, p. 307-312, 2006,

[14] Im,T.S. Component based programming in mobile devices: The future of mobile device development? . In Inst Informatics \&Systemic, p. 255-259, 2004.

[15] Maria Is Po., SIP-based Applications in UMTS: A Performance Analysis, Fifth European Wireless Conference, Mobile and Wireless Systems beyond 3G, Barcelona, Spain, 2004.

[16] I. Markota, I. Ćubić.. Medical Sensor Application Framework Based on IMS/SIP Platform. In Research \& Development Centre, Ericsson Nikola Tesla d.d. Croatia

[17] Gonzalo Camarillo and Miguel A. The 3G IP Multimedia Subsystem (IMS) Merging the Internet and the Cellular Worlds. In John Wiley \& Sons, Ltd. Publisher.

[18] Sike Huang. Mobile Telemedicine System based on IMS/SIP platform, Stockholm,

Sweden, page 9-10, 2009, Retrieved June $20^{\text {th }} 2011$ from

http://web.it.kth.se/ johanmon/theses/huang.pdf

\section{Authors Bibliography}

Dr. Ahmed Barnawi received his BSc in Electrical Engineering from King Abdul-Aziz University in 2000, his degree in Communication Engineering from University of Manchester Institute of Science and Technology (UMIST) in 2002, and his PhD degree in Mobile Communications from Bradford University in 2006. Currently, Dr. Barnawi is an Assistant Professor at the Department of Computer Science, King AbdulAziz University, Jeddah, Saudi Arabia. His current research interests include Mobile Next Generation Network, Cognitive Radio and Wireless Ad hoc and Sensor Networks.

Dr. Abdulrahman Altalhi is an assistant professor of Information Technology at King Abdul-Aziz University. He has obtained his Ph.D. in Engineering and Applied Sciences (Computer Science) from the University of New Orleans on May of 2004. He served as the chairman of the IT department for two years (2007-2008). Currently, he is the Vice Dean of the College of Computing and Information Technology. His research interest include: Wireless Networks, Software Engineering, and Computing Education.

Dr. M. Rizwan Jameel Qureshi, is an assistant Professor at IT Department, Faculty of Computing and Information Technology, King Abdul Aziz University, Jeddah, Saudi Arabia. He has done his Ph.D. CS (Software Process Improvement) in 2009. He is in the field of teaching and research since 2001. He has published twenty two research publications and six books at national and international forums. $\mathrm{He}$ is teaching Software Engineering domain courses at graduate and undergraduate level from more than ten years.

Mr. Asif Irshad Khan received his Bachelor and Master degree in Computer Science from the Aligarh Muslim University (A.M.U), Aligarh, India in 1998 and 2001 respectively. $\mathrm{He}$ is presently working as a Lecturer Computer Science at the Faculty of Computing and Information Technology, King Abdul Aziz University, Jeddah, Saudi Arabia. He has more than seven years experience of teaching as lecturer to graduate and undergraduate students in different universities and worked for four years in industry before joining academia full time. He has eight research publications and his research interest includes Software Engineering, Component Based Software Engineering and Agent Based Software Engineering.

\section{Appendixes}

\begin{tabular}{|l|}
\hline Student Questionnaire \\
\hline Applicability category \\
\hline Q1) How much Mobile based exam is acceptable to \\
you as compared to traditional exam? \\
\hline Q2) Do you believe automatic assessment of your \\
exam is fairer than if the exam was marked by your \\
instructor? \\
\hline Q3) In your opinion Voice Based Exam on Mobile \\
phone is effective assessment tool if compared to \\
Text Based Examination on Mobile phone. \\
\hline \\
\hline Usability (Appearance): \\
\hline Q1) Do you find easy while reading characters on \\
the screen? \\
\hline (Q2) Do you think organization of information is \\
excellent? \\
\hline Q3) Do you believe Sequence of screens and \\
interface of this system is pleasant? \\
\hline (Q4) Do you find the exam method is clear enough \\
and easy in remembering names and command? \\
\hline \\
\hline Affective (Factors): \\
\hline (Q1) Do you think exam on Mobile devices will \\
increases stress of exams? \\
\hline (Q2) Do you recommend mobiles devices to be used \\
as part of assessment in university? \\
\hline (Q3) How much it is hard to concentrate on the \\
questions when doing on mobile devices? \\
\hline (Q4) How much you are comfortable to do exams on \\
mobile device than on a paper? \\
\hline Pedagogy category \\
\hline Q1) Do you agree that the potential for immediate \\
results with mobile based system could help you \\
learn? \\
\hline (Q2) Do you believe the system will improve on your \\
learning process? \\
\hline
\end{tabular}


(Q3) Do you agree that Mobile based assessment is just a gimmick that does not really benefit learning.

\section{Security}

(Q1) Do you think Mobile based exam is just as secure as paper-based assessment.

(Q2) Do you believe it is easier to cheat on mobile based exams than that with paper-based exams

(Q3) Do you think Username and password login provide adequate security for mobile based exams

\section{Technicality: \\ (Q1) Do you have enough Mobile knowledge/experience to use a Mobile-based exam system for assessment purposes in Universities?}

(Q2) How complex do you think it would be to use Mobile-based exam for assessment purposes in Universities?

(Q3) Do you trust the technology? Do you think it is reliable to contact exam on Mobile devices

(Q4) Do you believe marking is more accurate, because computers don't suffer from human error?

(Q5) Do you agree that randomized questions from an exam bank means that sometimes you might get easier questions?

(Q6) Would you like to see number of questions you attempted correct as well as incorrect in your result?

\section{Faculty Questionnaire}

\section{Technicality category:}

(Q1) Do you agree that the current system of manual assessment of student is very time consuming?

(Q2) Do you agree that the current system of manual assessment of student requires a lot of effort?

(Q3) Do you agree that the current system of manual assessment of student consumes enormous resources? (Q4) How do you rate the possibility of loss of student records in the present manual assessment of student?

(Q5) Do you believe there is a level of need for automatic assessment of exams especially when group of student is too large in a course?

(Q6) How much Mobile based exam is secure as paper-based assessment in terms of paper leakage?

\section{Usability category}

(Q1) How easy you find setting of exam paper in present paper based examination process keeping in mind as it is a repetitive job?

(Q2) How do you rate the level of difficulty in

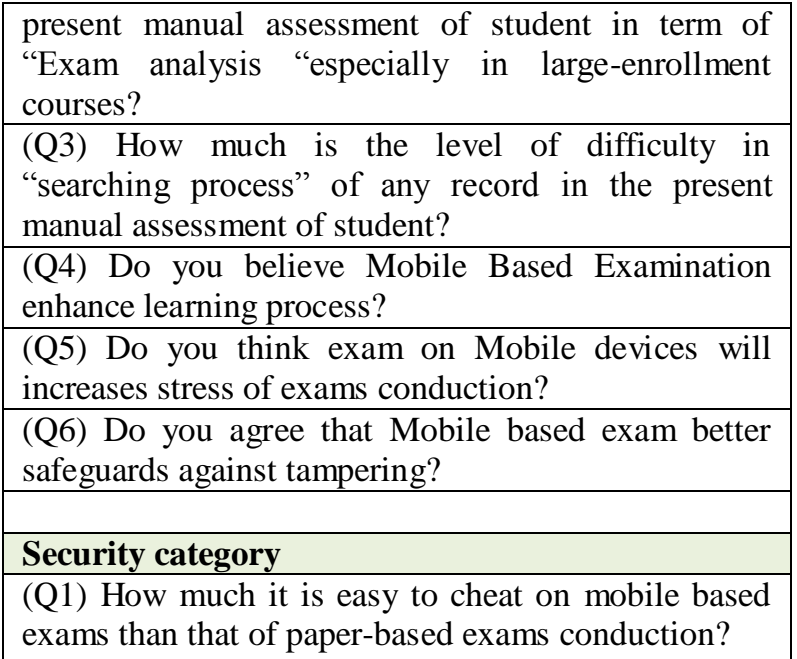

(Q2) Do you agree that randomized questions from an exam bank ease cheating?

\section{Applicability category}

(Q1) How much do you think Mobile based exam is acceptable to you as compared to traditional paper based exam?

(Q2) How much do you think automatic assessment of exam is fairer than if the exam was marked by you?

(Q3) How much do you think Mobile Based Examination system improves the exam conduction process if you compared with present manual system?

(Q4) How much Mobile Based Examination system improves the exam assessment process if you compared with present manual system?

(Q5) Do you believe that hand-writing on an exam influenced the scores to some degree?

(Q6) How much Mobile based exam is secure as paper-based assessment in terms of paper leakage? 